\title{
INVESTIGATION OF EFFICIENCY OF ADAPTIVE TECHNOLOGIES AND TECHNICAL MEANS FOR GROWING ENTOMOCULTURES
}

\author{
Valentyna Krutyakova ${ }^{1}$, Nonna Pishchanska ${ }^{1}$, Volodymyr Bulgakov ${ }^{2}$, Aleksandrs Adamovics ${ }^{3}$ \\ ${ }^{1}$ Engineering and Technology Institute "Biotechnica", Ukraine; \\ ${ }^{2}$ National University of Life and Environmental Sciences of Ukraine, Ukraine; \\ ${ }^{3}$ Latvia University of Life Sciences and Technologies, Latvia \\ aleksandrs.adamovics@1lu.lv
}

\begin{abstract}
Entomocultures is a perspective trend, and they find increasing application in the modern agricultural production. The growing and mass production technologies of entomocultures involve the use of technologies and a complex of equipment adapted to certain natural and climatic conditions providing increased efficiency of the technological processes for the production of entomological products. The technical requirements for the production lines of specific means of biological protection are characterised by significant variability, which determines the purposefulness of the designed approach in order to create technological lines for growing entomocultures. In order to assess the technology, as a whole, a generalised criterion was used, which characterises the minimum energy consumption or a maximum profit. To analyse the entire technology, taking into account several criteria, the indicators of each operation are summarised and presented both in physical terms and by its cost. The research showed that the entomocultures, grown using adaptive technologies that ensure the implementation of external climatic parameters of the environment used by the insects (temperature, humidity, lighting, the air flow) in the entomological laboratories for their production, are characterised by the quality indicators 1.2-1.3 times more in comparison with the entomocultures, obtained by other methods. The insects no longer need a period of adaptation to the climatic conditions in the places of their use. The maximum approximation of the characteristics of the cultivated insects according to the proposed technologies to the indicators of natural populations has been experimentally confirmed - the deviation is not more than $10 \%$. The energy efficiency indicators are increasing by $18-20 \%$, and the environmental safety indicators by $15 \%$. At the same time, the operating costs are reduced not less than by $27-30 \%$.
\end{abstract}

Keywords: entomocultures, production, equipment, quality.

\section{Introduction}

Efficient management of the technological process of growing entomocultures can be built only on the basis of a criteria-based comparative assessment of technologies for growing entomocultures, taking into account all the factors involved in the formation of the technological process and the initial indicators. The peculiarity in the process of growing entomocultures is that the microclimate parameters in the laboratory play a very significant role in the technological process, on which essentially depends the efficiency of the implementation of adaptive technologies and the insect quality indicators, which are the main indicators of evaluation, including the technologies themselves [1-3].

The technical requirements for the technologic production lines of specific biological protective means are characterised by significant variability, which determines the purposefulness of the project approach to creation of technological lines for growing entomocultures. The evaluation criteria for adaptive technologies and technical means ensure their optimisation, which is carried out according to one or several indicators simultaneously. One of the indicators acts as the main evaluation criterion (the objective function), and all the rest as limitations. The task of the analysis, according to one criterion, as a rule, arises during the operational management of the process of growing entomocultures and limited resources or the raw materials. The evaluation criteria are the quality indicators, the energy costs, the labour costs, the loss of entomoculture, the environmental indicators, etc. To assess the technologies, as a whole, a generalised criterion was used, characterising the minimum of energy costs or the maximum profit. To analyse the entire technology, taking into account several criteria, the indicators of each operation are summarized and presented both in physical terms and as a price.

The efficiency and modern technical level of machines and apparatus of entomological industries, like any other industrial product, is characterised by a group of quality indicators: indicators of purpose, reliability, safety, transportability, ergonomics, economy, as well as technical aesthetics, patent-legal and environmental indicators [4-6]. Application of the assessment criteria to analyse the 
results of designing and to verify the adequacy of entomological production technologies ensures the efficiency of their use [7;8].

\section{Materials and methods}

To analyse the quality of insects, general indicators were considered that assess the degree of fitness of the entomoculture for artificial breeding conditions, and target indicators that assess the degree of efficiency of the entomoculture in its application [9;10]. Analysis of the energy efficiency of the system is carried out in three main areas - standardised indicators of the energy efficiency of products, indicators of the energy efficiency of production processes and indicators of energy saving. For the environmental assessment of adaptive technologies the modern Life Cycle Assessment methodology is applied. There is a further possibility of optimising the adaptive technologies according to one or several criteria, one of which will be chosen as the main one, and the others will act as restrictions.

Evaluation of technologies by the indicators that characterise the efficiency of an individual technical means, or by a number of indicators, characterising the technological properties of the elements of a technology, does not fully reflect the advantages of this or that technology. It is purposeful to evaluate technologies according to the indicators of the economic, energy and environmental criteria, taking into account the total effect of all the technical means.

The trichogram quality indicators should be determined 3-4 times for one breeding period, including the determination of the searching ability. This indicator is determined using the OKI-1 device (Fig. 1).

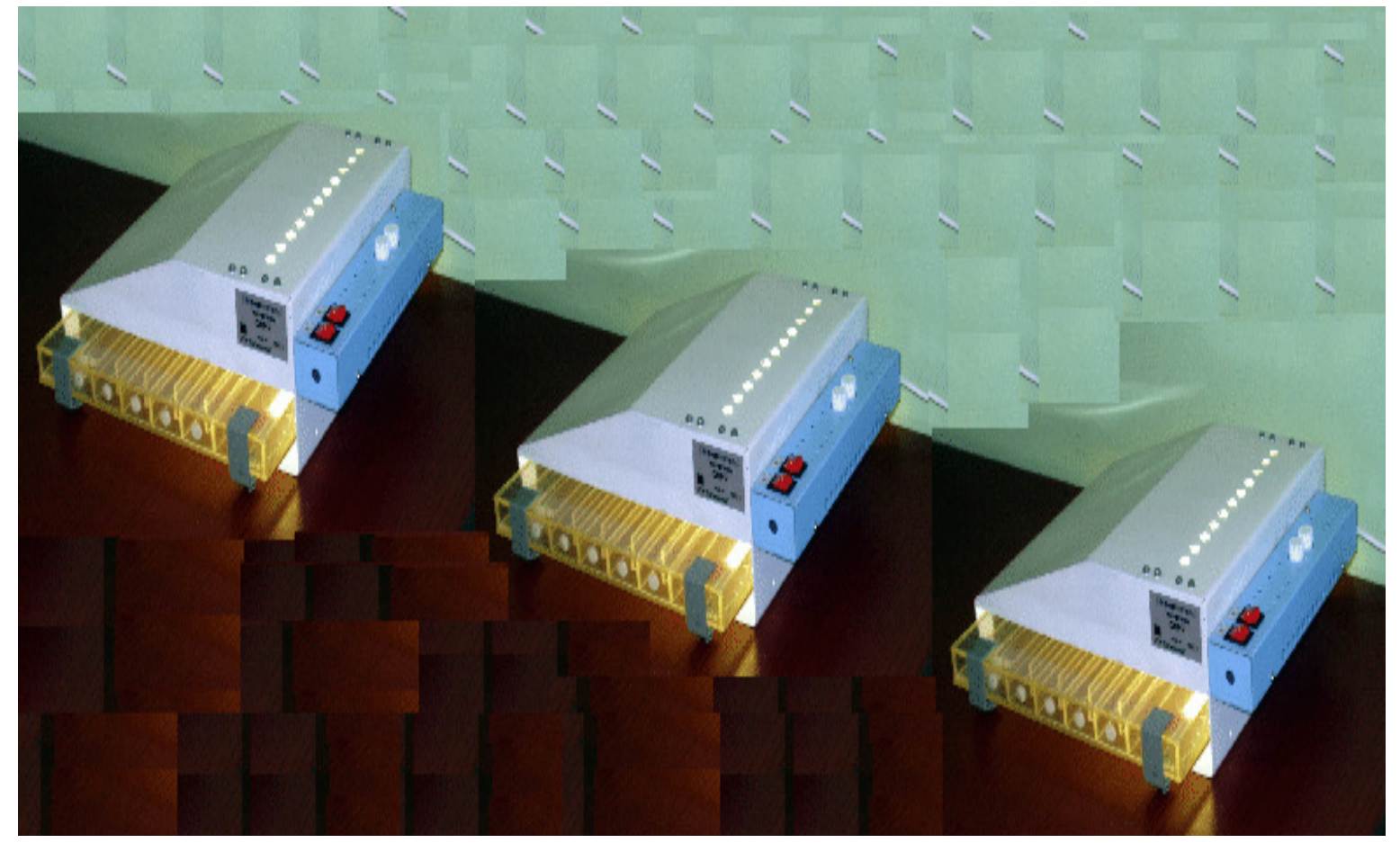

Fig. 1. Integrated device OKI-1 for quality measuring

(The studies are carried out on three OKI-1 simultaneously)

The OKI-1 quality measuring device consists of a camera with the sources of Fight ( 3 pcs), a power supply $(1 \mathrm{pc})$ and a thermostat $(1 \mathrm{pc})$. The camera consists of two compartments: the first compartment - for launching a trichogram, placing blackened eggs of the grain moth just before the egg-eaters departure; the second compartment - for placing cards with eggs of the pest - the inhabitant. The compartments are interconnected by a channel, the length of which is $3 \mathrm{~m}$, which corresponds to the radius of the efficient action of the trichogram under the field conditions.

The trichogram search ability index is estimated by the number of the infected eggs of the grain moth or natural feeders at the given hydrothermal regime (Fig. 2). 


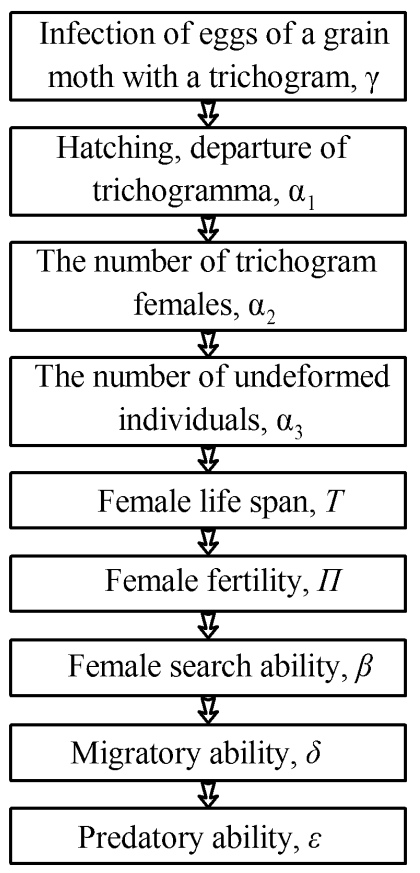

\section{Fig. 2. Flowchart of the current express-analysis of the efficiency of adaptive technologies for growing entomocultures}

In order to evaluate the search ability by the number (3-5 g) of eggs infected with a trichogram, three samples of $0.5 \mathrm{~g}$ each are taken, distributed into test tubes, $5-10 \mathrm{~cm} \mathrm{long}$, and $8-10 \mathrm{~mm}$ in diameter, tightly closed, kept until the beginning of summer at $25^{\circ} \mathrm{C}$.

Criteria for the assessment of the quality of trichograms can be analyzed according to the recommended data, presented in Table 1.

Trichogram quality assessment criteria

Table 1

\begin{tabular}{|c|c|c|}
\hline \multirow{2}{*}{ Class } & \multicolumn{2}{|c|}{ Expected efficiency, \% } \\
\cline { 2 - 3 } & General quality criterion, $y$ & Efficiency, \% \\
\hline 1 & $0.71-1.00$ & $>80$ \\
\hline 2 & $0.51-0.70$ & $60-80$ \\
\hline 3 & $0.31-0.50$ & $40-60$ \\
\hline
\end{tabular}

One of the main criteria for the assessment of the introduction of adaptive technologies is the quality of insects. To assess the quality of entomological products, the indicators are divided into the general and the target ones. When breeding uterine entomoculture, the monitoring of general quality indicators is mandatory. In the mass production of entomoproducts, the control of the target quality indicators takes place in accordance with the current normative documents, and, if necessary, the overall quality indicators are also monitored. The general indicators evaluate the degree of fitness of the entomoculture to the artificial breeding conditions. The target indicators measure the efficiency of insects in their use. The introduction of adaptive technologies has a significant impact just upon target indicators. The general quality indicators include: the mass of insects; the size of insects or parts of their bodies; the duration of the development of a generation; the duration of the development of individual stages of ontogenesis of the insects; the insect survival; the rebirth of the insects; the adult (imago) sex index; the actual fertility of the females; the entomoculture reproduction factor.

The quality of entomophages is determined by three main target indicators - the search activity $\beta$, the migration activity $\delta$, the predatory activity $\varepsilon$. The investigations by the authors, including the Biotechnics Institute, proved the impact of the adaptive technology components (the preset temperature and humidity conditions, the day-night simulation, the air movement, etc.) upon the insect quality: 


$$
\beta=\frac{\sum N_{i}^{z a r}}{\sum N} ; \delta=\frac{\sum N_{i}^{p r i s}}{\sum N} ; \varepsilon=\frac{\sum N_{i}^{z a r}}{\sum N},
$$

where $\sum N-$ total amount of the entomoculture;

$\sum N_{i}^{z a r}$ - number of the infected insects;

$\sum N_{i}^{p r i s}$ - number of insects reaching the target.

\section{Results and discussions}

Under experimental conditions the trichogram adaptability was evaluated in various temperature conditions. For the study two target indicators were selected that reflect a possibility for a female trichogram to find the eggs of natural hosts: the searching activity and the migratory activity.

It was established that the widest range of favourable temperatures (at which the search activity of the females exceeds 0.5 ) and the highest search activity (0.75) displayed the natural population of the trichogram (Fig. 3). As close as possible to the natural population is a trichogram, which was bred according to a new technique, developed by us (0.69). Regarding the techniques of other authors, the results of the trichogram activity in the 3rd version were obtained at a high level.

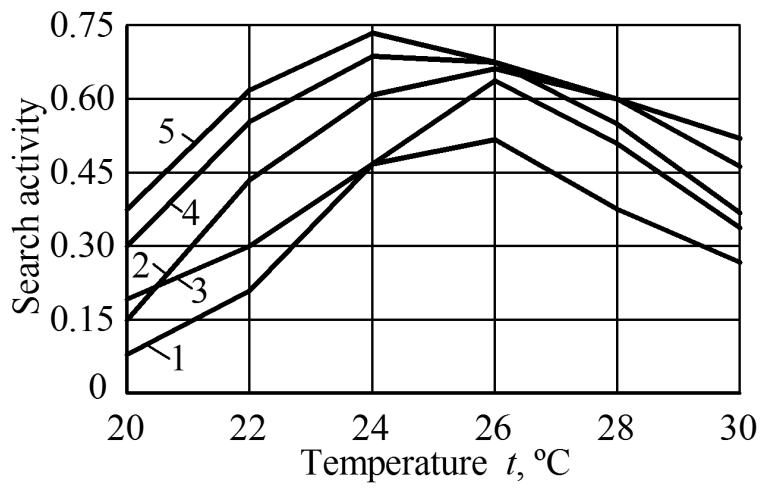

Fig. 3. Search activity of trichograms at various temperatures: 1 - working culture of E1110O; 2 - population by the method of Rezniketall, 2010; 3 - population by an experimental methodology, 1983; 4 - population by the experimental methodology; 5 - natural population

As the graphs in Fig. 3 show, the trichogram had maximum search activity in the 2nd variant; however, there was a significantly smaller range of favourable temperatures. The indicators of the working culture can be called satisfactory only at a temperature of $26^{\circ} \mathrm{C}$.

Similar were the results of our experimental studies to assess the migratory ability of the trichogram, presented in Fig. 4.

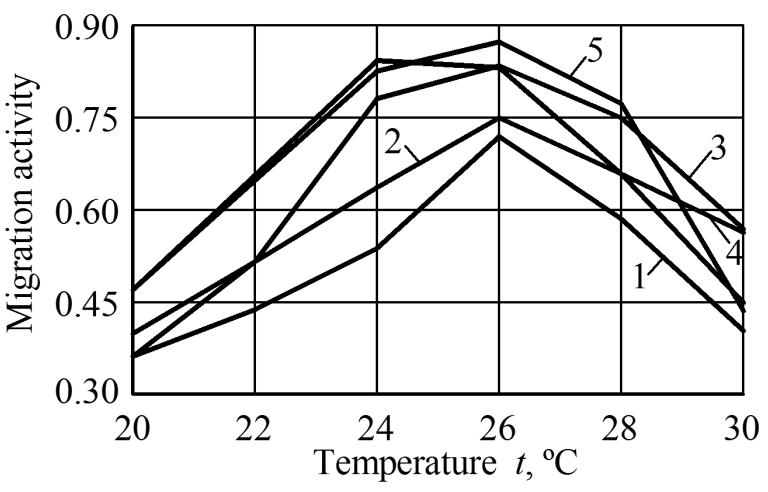

Fig. 4. Migration activity of the trichogram at different temperatures: 1 - working culture of E1110O; 2 - population by the method of Reznik et all., 2010; 3 - population by the experimental technique of 1983; 4 - population by experimental methods; 5 -natural population 
The results of the research showed that the individuals of the natural trichogram population had higher viability and adaptability to various temperature conditions. The use of the experimental trichogram dilution technique at variable temperatures allowed us to approach the indicators of natural populations. The methodologies of other authors had a significant effect; however, it was evident that such conditions are not optimal for the given culture, and, accordingly, the methodologies require correction for each local population separately.

We also conducted experimental investigations on the example of growing grain moths, using forced air movement organisation with optimal parameters (temperature, relative humidity, speed) through air ducts, uniformly arranged by their volume. This ensured convective heat dissipation and maximum entomoproduction.

The production activities in the sphere of energy conservation are characterised by comparative indicators of energy consumption and energy intensity of production, as well as absolute, specific and relative indicators of energy consumption, losses of the energy resources in the course of economic activity (Fig. 5).

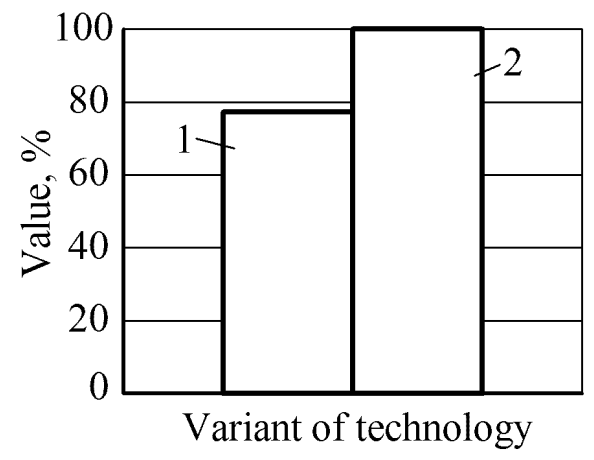

Fig. 5. Energy analysis of alternative technologies for growing entomocultures:

1 - adaptive technologies; 2 - regulated technologies

In assessing the impact on the depletion of natural resources, the depletion of mineral and fuel resources is determined. A large base has been developed to determine the quality and quantity of harmful effects and emissions in the production of certain materials. This base is necessary for the $L C A$ calculation program (Fig. 6).

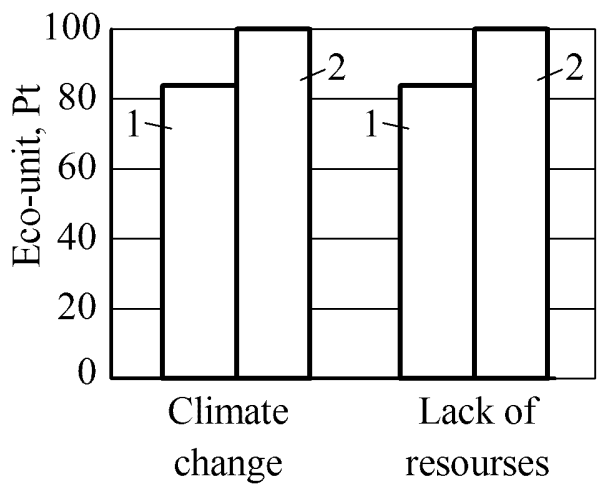

Fig. 6. Environmental impact of alternative technologies over the full life cycle: 1 - adaptive technologies; 2 - regulated technologies

An economic comparison of alternative technologies with the creation of the basic microclimate system has been carried out. Proposed for consideration are microclimate preparation systems, using energy-saving technologies. The economic costs of the development and implementation of an air conditioning system, using the geothermal sources of cold, are almost 5 times less than for the air conditioning system with a basic cooling system (Fig. 7).

The implementation cost of an air conditioning system using alternative energy sources is almost 10 times higher than for the microclimate preparation system using the basic technology. Compared with the basic system of using alternative sources, it has several advantages - it provides low 
operating costs, shorter payback periods, and ensures complete independence from the general power supply line $[9 ; 10]$. These factors point to the efficiency of functioning and competitiveness of the alternative system.

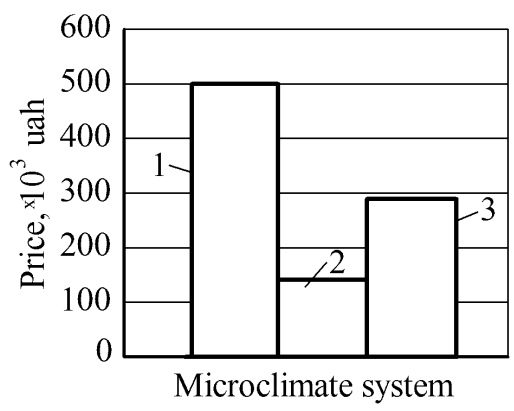

Fig. 7. Economic comparison of air preparation systems for technological premises for growing insects: 1 - alternative energy sources; 2 - geothermal energy; 3 - basic system

\section{Conclusions}

1. The main initial conditions for forming an assessment for the implementation of adaptive technologies for growing entomocultures are: for the quality of the entomoculture - the search activity, the migratory and predatory; for energy efficiency - indicators of the quality of the entomoculture, the amount of energy used, the introduction of energy-saving technologies; for economic - the cost and volume of energy and labour, the cost and amount of the entomoculture, the cost and amount of metal consumption; for environmental assessment - the impact on insects, depletion of resources, the environmental impact, the technology accident rate.

2. The entire stage of formation of the given conditions of an effective complex of technical means for the implementation of adaptive technologies is investigated and regulated, and adaptive technologies are analysed, using the example of trichogram growing. The environmental, economic and energy analyses of the two systems have shown the benefits of using the adaptive technologies.

3. The research showed that the entomocultures, grown using adaptive technologies that ensure the implementation of external climatic parameters of the environment used by the insects (temperature, humidity, lighting, the air flow) in the entomological laboratories for their production, are characterised by the quality indicators 1.2-1.3 times more in comparison with the entomocultures, obtained by other methods. The insects no longer need a period of adaptation to the climatic conditions in the places of their use. The maximum approximation of the characteristics of the cultivated insects according to the proposed technologies to the indicators of natural populations has been experimentally confirmed - the deviation is not more than $10 \%$. The energy efficiency indicators are increasing by $18-20 \%$, and the environmental safety indicators by $15 \%$. At the same time, the operating costs are reduced not less than by $27-30 \%$.

\section{References}

[1] Cohen A.C. Ecology of Insect Rearing Systems: A Mini-Review of Insect Rearing Papers from 1906-2017. Advances in Entomology, 2018, Vol. 6 (2). pp. 86-115.

[2] Krutiakova V., Bespalov I., Bulgakov V., Viesturs D. Engineering design of industrial production of golden-eyed lacewings ( $l$. chrysoperla carnea steph) in the programs of biological protection of plants. Engineering for rural development, Vol.18, 2019, pp.278-283.

[3] Ghosh S., Haldar P., Mandal D.K. Suitable food plants for mass rearing of the short-horn grasshopper Oxya hyla hyla (Orthoptera: Acrididae). Eur. J. Entomol., 111 (3), 2014, pp. 448-452.

[4] Leppla N.C., Ashley T.R., Quality control in insect mass production: A review and model. Bull. Entomol. Soc. Am. 70, 1989, pp. 33-44.

[5] Raubenheimer D., Rothman J.M. Nutritional Ecology of Entomophagy in Humans and Other Primates. Annu. Rev. Entomol, Vol. 58, 2013, pp. 141-160.

[6] Lenteren J.C. The state of commercial augmentative biological control: plenty of natural enemies, but a frustrating lack of uptake. BioControl, Vol. 57, No. 1, 2012, pp. 1-20. 
[7] Ghazy N.A., Suzuki T., Amano H., Ohyama K. Humidity-controlled cold storage of Neoseiulus californicus (Acari: Phytoseiidae): effects on male survival and reproductive ability. Journal of Applied Entomology. 2013, Vol. 137, Issue 5. pp. 376-382.

[8] Dortel E., Thuiller W., Lobo J. M., Bohbot H., Lumaret, Jay-Robert J. P. P. Potential effects of climate change on the distribution of Scarabaeidae dung beetles in Western Europe. Journal of Insect Conservation, 17 (5), 2013, pp. 1059-1070.

[9] Беспалов I.М., Бельченко В.М., Шейкін Б.М., Барабаш А.Д., Лешишак О.В., Бородавкіна Т.В. Кліматична техніка у технологічних процесах промислової ентомології (Climatic engineering in technological processes of industrial entomology). Міжвідомчий тематичний збірник “Вісник аграрної науки Південного регіону”, No.1, 2014. C. 69-74. (In Ukrainian).

[10] Van Lenteren J.C. The state of commercial augmentative biological control: plenty of natural enemies, but a frustrating lack of uptake. BioControl, 2012, Vol. 57, Issue 1. pp. 1-20. 